\title{
Solving Two-Points Singular Boundary Value Problem Using Hermite Interpolation
}

\author{
Heba A. Abd Al-Razak \\ Department of Mathematics, College of Science for Women, University of Baghdad. \\ Received 3, September, 2014 \\ Accepted 5, February, 2015 \\ cc) $(1)$
}

NoDerivatives 4.0 International Licens

Abstract:

In this paper, we have been used the Hermite interpolation method to solve second order regular boundary value problems for singular ordinary differential equations. The suggest method applied after divided the domain into many subdomains then used Hermite interpolation on each subdomain, the solution of the equation is equal to summation of the solution in each subdomain. Finally, we gave many examples to illustrate the suggested method and its efficiency.

Keywords: Singular ordinary differential equations, Boundary value problems, Hermite interpolation.

\section{Introduction:}

Singular boundary value problems (SBVP's) for ordinary differential equations (ODE) arise very frequently in several areas of science and engineering. For example, in analysis of heat conduction through a solid with heat generation, Thomas-Fermi model in atomic physics, electro hydrodynamics and the theory of thermal explosions. These arise in Physiology as well in the study of various tumor growth problems, in the study of the distribution of heat sources in the human head[1-3]. Singular boundary value problems are always very important, there exists many method for solving. For example, modified Homotopy perturbation method [4], differential transform method [5], cubic trigonometric B-spline method[6], Adomian decomposition method [7], shooting method [8], variation method[9].

Hermite interpolation method which was mooted by charts Hermite is often used in interpolation of the data points when the derivative of the function $\mathrm{f}(\mathrm{x})$ in the given points are available this technique has superiority on the other types of interpolation polynomial [10].

In this paper we will use Hermite interpolation method for solving singular boundary value problems of ODE after divided the interval $[0,1]$ into many subdomains equal distance. Numerical examples show that present method is efficiency.

\section{Hermite Interpolation [11]}

Weierstrass approximation theorem guarantees that one can always find a polynomial that is arbitrarily close to a given function on some finite interval. This means that the approximation error is bounded and can be reduced by the choice of the adequate polynomial. Unfortunately this theorem is not a constructive one, i.e., it does not present a way how to obtain such a 
polynomial, i.e., the interpolation problem can also be formulated in another way, viz. as the answer to the following question: How to find a good representative of a function that is not knew explicitly, but only at some points of the domain of interest. In this paper we will consider Hermite interpolation where the interpolation polynomial also matches the first derivatives $\mathrm{f}^{(1)}(\mathrm{x})$ at $x=x_{k}$. This interpolation technique is important since it has the property that gives high order of accuracy.

Theorem 1:[11] Suppose that $\mathrm{f}(\mathrm{x}) \in$ $C^{1}[\mathrm{a}, \mathrm{b}]$, and that $x_{o}, x_{1}, \ldots, x_{n} \in[a, b]$ are distinct, then the unique polynomial of degree (at most) $2 n+1$ denoted by $H_{2 n+1}$, and such that :

$H_{2 n+1}\left(x_{j}\right)=f\left(x_{j}\right), H_{2 n+1}^{\prime}\left(x_{j}\right)=$ $f^{\prime}\left(x_{j}\right) \quad j \in Z_{n+1}$ is given by :

$H_{2 n+1}(x)=\sum_{k=0}^{n}\left[1-2 L_{k}^{\prime}\left(x_{k}\right)(x-\right.$ $\left.\left.x_{k}\right)\right]\left[L_{k}(x)\right]^{2} f\left(x_{k}\right)+\sum_{k=0}^{n}(x-$

$\left.x_{k}\right)\left[L_{k}(x)\right]^{2} f^{\prime}\left(x_{k}\right)$

$L_{k}(x)=\prod_{\substack{i=0 \\ i \neq j}}^{n} \frac{x-x_{i}}{x_{k}-x_{i}}$

The error bound for Hermite interpolation is provided by the expression:

$\mathrm{E}=\left(x-x_{o}\right)^{2}\left(x-x_{1}\right)^{2} \ldots(x-$

$\left.x_{n}\right)^{2} f^{(2 n+1)}(x) /(2 n+1)$ !, where

$\mathrm{f}(\mathrm{x}) \in C^{2 n+2}[a, b]$.

2. Singular Boundary Value Problem

The general form of the $2^{\text {nd }}$ order two point boundary value problems (TPBVP) is:

$y^{\prime \prime}+p(x) y^{\prime}+Q(x) y=0, a \leq x \leq$ $b$... (2)

With the boundary conditions $(\mathrm{BC}): \mathrm{y}(\mathrm{a})=\mathrm{A}$ and $\mathrm{y}(\mathrm{b})=\mathrm{B}$, where $\mathrm{A}$, $\mathrm{B} \in \mathrm{R}$

There are two types of a point $x_{o} \in[0,1]$.Ordinary point and Singular point.A function $\mathrm{y}(\mathrm{x})$ is analytic at $x_{o}$ if it has a power series expansion at $x_{o}$ that converges to $\mathrm{y}(\mathrm{x})$ on an open interval containing $x_{o}$. A point $x_{o}$ is an ordinary point of the ODE (2), if the functions $\mathrm{P}(\mathrm{x})$ and $\mathrm{Q}(\mathrm{x})$ are analytic at $x_{o}$. Otherwise $x_{o}$ is a singular point of the ODE. On the other hand if $\mathrm{P}(\mathrm{x})$ or $\mathrm{Q}(\mathrm{x})$ are not analytic at $x_{o}$ then $x_{0}$ is said to be a singular point [1213].There is at present, numerical method for solving problems with regular singular points using Hermite interpolation method with interval [0 1].

\section{Description of the Method}

In this section, we apply the Hermite interpolation method $\mathrm{H}_{2 n+1}$ and Taylor series to solve regular differential equations. A general form of the $2^{\text {nd }}$ order SBVP's is:

$$
\begin{gathered}
x^{m} y^{\prime \prime}=f\left(x, y, y^{\prime}\right), \quad 0 \leq x \\
\leq 1 \ldots(3)
\end{gathered}
$$

Subject to the boundary condition (BC):

In the case Dirichlet $\mathrm{BC}: \mathrm{y}(0)=\mathrm{A}, \mathrm{y}(1)$ $=\mathrm{B}$, where $\mathrm{A}, \mathrm{B} \in \mathrm{R}$

In the case Neumann $B C: y^{\prime}(0)=A$, $\mathrm{y}^{\prime}(1)=\mathrm{B}$, where A, B $\in \mathrm{R}$

In the case Cauchy or mixed $B C: y(0)=$ $\mathrm{A}, \mathrm{y}^{\prime}(1)=\mathrm{B}$, where $\mathrm{A}, \mathrm{B} \in \mathrm{R}$

Or $\mathrm{y}^{\prime}(0)=\mathrm{A}, \mathrm{y}(1)=\mathrm{B}$, where $\mathrm{A}, \mathrm{B} \epsilon$ $\mathrm{R}$

where $\mathrm{f}$ is a general nonlinear function . Now, to solve the problem by the suggested method we will doing the following steps:

Step one: Evaluate Taylor series of $\mathrm{y}(\mathrm{x})$ about $\mathrm{x}=0$ :

$y(x)=\sum_{i=0}^{\infty} a_{i} x^{i}=a_{o}+a_{1} x+$

$\sum_{i=2}^{\infty} a_{i} x^{i} \ldots(4)$

Where $\quad \mathrm{y}(0)=a_{o}, \mathrm{y}^{\prime}(0)=a_{1} \quad \frac{y^{\prime \prime}(0)}{2 !}$ $=a_{2}, \ldots, \frac{y^{(i)}(0)}{i !}=a_{i}, \mathrm{i}=3,4, \ldots$

Evaluate Taylor series of $\mathrm{y}(\mathrm{x})$ about $\mathrm{x}$ $=1 / 3$ :

$y(x)=\sum_{i=0}^{\infty} b_{i}(x-1 / 3)^{i}=b_{o}+$ $b_{1}(x-1 / 3)+\sum_{i=2}^{\infty} b_{i}(x-$

$1 / 3)^{i} \ldots(5)$

Where $\mathrm{y}(1 / 3)=b_{o}, \mathrm{y}^{\prime}(1 / 3)=b_{1} \quad \frac{y^{\prime \prime}(1 / 3)}{2 !}$ $=b_{2}, \ldots, \frac{y^{(i)}(1 / 3)}{i !}=b_{i}, \mathrm{i}=3,4, \ldots$ 
Evaluate Taylor series of $\mathrm{y}(\mathrm{x})$ about $\mathrm{x}$ $=2 / 3$ :

$y(x)=\sum_{i=0}^{\infty} c_{i}(x-2 / 3)^{i}=c_{o}+$ $c_{1}(x-2 / 3)+\sum_{i=2}^{\infty} c_{i}(x-$ $2 / 3)^{i} \ldots(6)$

Where $\mathrm{y}(2 / 3)=c_{o}, \mathrm{y}^{\prime}(2 / 3)=c_{1} \quad \frac{y^{\prime \prime}(2 / 3)}{2 !}$ $=c_{2}, \ldots, \frac{y^{(i)}(2 / 3)}{i !}=c_{i}, \mathrm{i}=3,4, \ldots$

And evaluate Taylor series of $\mathrm{y}(\mathrm{x})$ about $\mathrm{x}=1$ :

$y(x)=\sum_{i=0}^{\infty} d_{i}(x-1)^{i}=d_{o}+$

$d_{1}(x-1)+\sum_{i=2}^{\infty} d_{i}(x-1)^{i} \ldots(7)$

Where $\quad \mathrm{y}(1)=d_{o}, \mathrm{y}^{\prime}(1)=d_{1} \quad \frac{y^{\prime \prime}(1)}{2 !}$ $=d_{2}, \ldots, \frac{y^{(i)}(1)}{i !}=d_{i}, \mathrm{i}=3,4, \ldots$

Step two: Insert the series form (4) with derivatives into equation (3) and put $\mathrm{x}=0$, then equate the coefficients of powers of $x$ to obtain $a_{2}$.Then derive equation(3) with respect to $\mathrm{x}$, to get new form of equation say(8) as following:

$x^{m} y^{\prime \prime \prime}(x)+m y^{\prime \prime}(x) x^{m-1}=$ $\frac{d f\left(x, y, y^{\prime}\right)}{d x} \ldots(8)$

Then insert the series form (4) with derivatives into equation (8) and put $\mathrm{x}=0$ equate the coefficients of power of $\mathrm{x}$ to obtain $a_{3}$.Iterate this process many times to obtain $a_{4}$ then $a_{5}$ and so on.

Step three: Make up $x=1 / 3$ into equation (4) to obtain $\mathrm{y}(1 / 3)=b_{o}$,to find $b_{1}$ derive the equation(4)and requite $x=1 / 3$, and insert the series (5) into equation (3) and put $x=1 / 3$,then equate the coefficients of power of $(\mathrm{x}-$ $1 / 3$ ) to obtain $b_{2}$.to find $b_{3}$ insert the series (5) into equation (8) and put $x=1 / 3$ and equate the coefficient of power of $(x-1 / 3)$. Iterate this process many times to obtain $b_{4}$ then $b_{5}$ and so on.

Step four: Make up $x=2 / 3$ into equation (5) to obtain $\mathrm{y}(2 / 3)=c_{o}$, to find $c_{1}$ derive the equation(5)and requite $x=2 / 3$, and insert the series (6) into equation (3) and put $x=2 / 3$, then equate the coefficients of power of $(x-$
2/3) to obtain $c_{2}$.to find $c_{3}$ insert the series (6) into equation (8) and put $x=2 / 3$ and equate the coefficient of power of $(x-2 / 3)$. Iterate this process many times to obtain $c_{4}$ then $c_{5}$ and so on.

Step five: Insert the series form (7) with derivatives into equation (3) and put $\mathrm{x}=1$, then equate the coefficients of powers of $(x-1)$ to obtain $d_{2}$,to find $d_{3}$ insert the series(7) with derivatives into equation (8) and put $x=1$ and equate the coefficient of power of $(x-1)$. Iterate this process many times to obtain $d_{4}$ then $d_{5}$ and so on.

Step six: The notation implies that the coefficients depend only on the indicated unknowns $a_{o}, a_{1}, d_{o}$ and $d_{1}$ where $c_{i}, b_{i} \forall i \geq 1$ dependes on the indicated unknowns $a_{o}, a_{1}$

When the substitute (BC) we get two unknown coefficients and then substitute for coefficients $\left(a_{i}, b_{i}, c_{i}, d_{i}\right)$ that we have obtained the previous steps in Hermite interpolation polynomial $H_{2 n+1}$ equation(1).

Step seven: To find the unknown coefficients by reduction order equation and use $H_{2 n+1}$ as a replacement of $\mathrm{y}(\mathrm{x})$ and substitute the boundary conditions, we have only two unknown coefficients from $a_{o}, a_{1}, d_{o}$ and $d_{1}$ and two equation, we can find this for any $\mathrm{n}$ by solving this system of algebraic equations. So insert the value of the unknown coefficients into equation (1),Thus equation (1) represent the solution of the problem.

\section{Error Estimation for SBVP's}

Every known of BVPs software package reports an estimate of either the relative error or the maximum relative defect. The weights used to scale either the error or the maximum defect differ among BVPs software. Therefore, the BVPs allows users to select the weights they wish to use. The default weights depend on whether 
an estimate of the error or maximum defect is being used. If the error is being uses estimated, in this paper we modify this package to consist SBVPs, defined as :

$\mathrm{E}=\left\|y(\mathrm{x})-H_{2 n+1}(\mathrm{x})\right\|_{\infty} /(1+\|$ $\left.H_{2 n+1}(\mathrm{x}) \|_{\infty}\right) ; 0 \leq x \leq 1$ where $\mathrm{y}(\mathrm{x})$ is exact solution and $H_{2 n+1}$ (x) is suggested solution of SBVPs .

If the exact solution does not find then the component error of SBVPs is $\mathrm{E}=\| H_{2 n+1}$ "(x) $-\mathrm{f}\left(\mathrm{x}, H_{2 n+1}(\mathrm{x})\right.$, $\left.H_{2 n+1}(\mathrm{x})\right) \|_{\infty} /\left(1+\| \mathrm{f}\left(\mathrm{x}, H_{2 n+1}(\mathrm{x})\right.\right.$, $\left.\left.H_{2 n+1}(\mathrm{x})\right) \|_{\infty}\right)$

The relative estimate of both the error and the maximum defect are slightly modified from the one used in SBVP SOLVER[ 14] .

\section{Numerical Examples:}

In this section, we used Hermite interpolation and Taylar series to solve singular boundary value problems (SPVBs).After the domain $[0,1]$ is divided into two points with points 0,1 where you found polynomial solution $\mathrm{H}_{7}(\mathrm{x})$ and presented the results the Variational iteration method and the exact solution, and the domain $[0,1]$ is divided into four points with points 0,1 where you found polynomial solution $\mathrm{H}_{11}(\mathrm{x})$, also the domain $[0,1]$ is divided into night points with points 0,1 where you found polynomial solution $\mathrm{H}_{21}(\mathrm{x})$. Then examples calculated maximum error in each case $n=4,6,11$ with figure polynomials to find a good solution.

Example1. Consider the following SBVP :

$$
y^{\prime \prime}+\frac{2}{x} y^{\prime}+\left(x^{2}-1\right) y=-x^{4}+
$$

$2 x^{2}-7, \quad 0 \leq \mathrm{x} \leq 1$

with mixed BC: $\mathrm{y}^{\prime}(0)=0, \mathrm{y}(1)=1$. The exact solution is : $y(x)=1-x^{2}$ [15] Using Taylor polynomials, we have $\mathrm{y}(0)=1, \mathrm{y}(1 / 3)=0.8888888888888889$, $\mathrm{y}(2 / 3)=, 0.5555555555555555$ $y^{\prime}(1 / 3)=\quad-0.6666666666666667$, $\mathrm{y}^{\prime}(2 / 3)=-1.333333333333333, \mathrm{y}^{\prime}(1)=-$ 2
Now, we solve this equation using these data

$$
\begin{aligned}
& \mathrm{H}_{7}(\mathrm{x})=\quad 9.14823772310^{-14} x^{7} \text { - } \\
& 3.26849658410^{-13} x^{6} \\
& 4.22772927810^{-13} x^{5} \\
& 2.66453525910^{-13} x^{4}+ \\
& 7.86037901410^{-14} x^{3}-1.0 x^{2}+1.0
\end{aligned}
$$

Geng [15] solved this example by (VIM) and give the following series solution:

$$
\begin{aligned}
& \mathrm{p}(\mathrm{x})=0.999997-x^{2}+1.2347 \\
& 10^{-7} x^{4}+ \\
& 0.0000165329 x^{8}- \\
& 0.0000201421 x^{10}+7.9588810^{-6} x^{12}- \\
& 1.030721^{-6} x^{14}
\end{aligned}
$$

The numerical results are given in following Table 1 gives $\mathrm{H}_{7}(\mathrm{x})$ and result VIM also exact solution. Table 2 gives the maximum error for number point $n=4,6,11$. Figure 1 gave the accuracy of the suggested method.

\section{Table 1: Numerical results for $n=4$} of example 1

\begin{tabular}{|c|c|c|c|}
\hline $\mathrm{x}_{\mathrm{i}}$ & $\begin{array}{c}\text { Exact Solution } \\
\mathrm{y}(\mathrm{x})\end{array}$ & $\begin{array}{c}\text { Hermite } \\
\text { interpolation } \\
H_{7}(\mathrm{x})\end{array}$ & VIM p(x) \\
\hline 0 & 1 & 1 & 0.999997000000000 \\
\hline 0.1 & 0.990000000000000 & 0.990000000000000 & 0.989997000012525 \\
\hline 0.2 & 0.960000000000000 & 0.960000000000000 & 0.959997000238787 \\
\hline 0.3 & 0.910000000000000 & 0.910000000000001 & 0.909997001980789 \\
\hline 0.4 & 0.840000000000000 & 0.8400000000000001 & 0.839997012074748 \\
\hline 0.5 & 0.750000000000000 & 0.750000000000002 & 0.749997054738341 \\
\hline 0.6 & 0.640000000000000 & 0.6400000000000003 & 0.639997189102191 \\
\hline 0.7 & 0.510000000000000 & 0.510000000000004 & 0.509997518669322 \\
\hline 0.8 & 0.360000000000000 & 0.360000000000005 & 0.359998167043863 \\
\hline 0.9 & 0.190000000000000 & 0.190000000000007 & 0.189999194602654 \\
\hline 1 & 0 & $8.43769498715119 \mathrm{e}-$ & $\begin{array}{c}4.57128800035456 \mathrm{e}- \\
15\end{array}$ \\
\hline
\end{tabular}

Table 2: The result maximum error when $n=4,6,11$ of example 1

\begin{tabular}{|c|c|c|c|}
\hline $\begin{array}{c}\mathrm{E} \\
\text { ror }\end{array}$ & $\begin{array}{c}\text { Hermite } \\
\text { interpolatio } \\
\mathrm{n} H_{7}(\mathrm{x})\end{array}$ & $\begin{array}{c}\text { Hermite } \\
\text { interpolatio } \\
\mathrm{n} H_{11}(\mathrm{x})\end{array}$ & $\begin{array}{c}\text { Hermite } \\
\text { interpolatio } \\
\mathrm{n} H_{21}(\mathrm{x})\end{array}$ \\
\hline $\mathrm{M}$. & 4.21884749 & 2.31020758 & 3.03624319 \\
$\mathrm{E}$ & $357560 \mathrm{e}-15$ & $079126 \mathrm{e}-12$ & $630824 \mathrm{e}-07$ \\
\hline
\end{tabular}




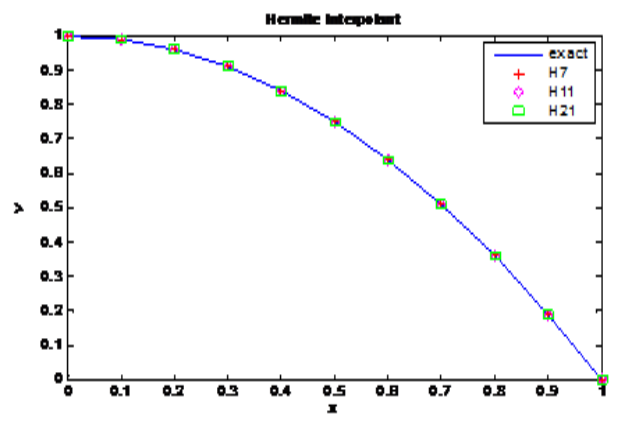

Fig.1: Comparison between the exact and suggested solution when $n=4$, 6,11

Example2. Consider the following SBVP : $\quad y^{\prime \prime}+\frac{2}{x} y^{\prime}-4 y=-2$, $0 \leq \mathrm{x} \leq 1$

with mixed BC: $\mathrm{y}^{\prime}(0)=0, \mathrm{y}(1)=5.5$. The exact solution is : $\mathrm{y}(\mathrm{x})=0.5+$ $\frac{5 \sinh (2 x)}{x \sinh (2)}$ [15]

Using Taylor polynomials, we have $\mathrm{y}(0)=3.257205700320381, \mathrm{y}(1 / 3)=$ $3.466030095098947, \quad \mathrm{y}(2 / 3)=$ 4.1499242047031 $y^{\prime}(1 / 3)=1.280759726616932, y^{\prime}(2 / 3)=$ 2.915149400050196, $\quad y^{\prime}(1)=$ 5.373147016441

Now, we solve this equation using these data

$\mathrm{H}_{7}(\mathrm{x})=0.009130738291121613 x^{7}+$ $0.01920841575611729 x^{6}+$

$0.01361484275073988 x^{5}+$

$0.3613904331003707 x^{4}+$

$0.001445668149072448 x^{3}+$

$1.838004201632197 x^{2}+$

3.257205700320381

Geng [15] solved this example by (VIM) and give the following series solution:

$\mathrm{p}(\mathrm{x})=3.25721+1.83814 x^{2}+$ $0.367628 x^{4}+$

$0.0350121 x^{6}+0.00194512 x^{8}+$

$0.0000707316 \mathrm{x}^{10}$

The numerical results are given in and Table 3 gives $H_{7}(x)$, results VIM exact solution. Table 4 gives the maximum error for number point $n=4,6,11$. Figure 2 gives the accuracy of the suggested method.
Table 3: Numerical results for $n=4$ of example 2

\begin{tabular}{|c|c|c|c|}
\hline $\mathrm{x}_{\mathrm{i}}$ & $\begin{array}{c}\text { Exact Solution } \\
\mathrm{y}(\mathrm{x})\end{array}$ & $\begin{array}{c}\text { Hermite } \\
\text { interpolation } \\
H_{7}(\mathrm{x})\end{array}$ & VIM $\mathrm{p}(\mathrm{x})$ \\
\hline 0.1 & 3.27562381647618 & 3.27562348331808 & 3.27562819783156 \\
\hline 0.2 & 3.33132158129189 & 3.33132136138556 & 3.33132605056115 \\
\hline 0.3 & 3.42564142056487 & 3.42564145791085 & 3.42564603865789 \\
\hline 0.4 & 3.56086353732463 & 3.56086354389276 & 3.56086836853219 \\
\hline 0.5 & 3.74027136831943 & 3.74027129054089 & 3.74027648126133 \\
\hline 0.6 & 3.96824614512855 & 3.96824615761122 & 3.96825161157128 \\
\hline 0.7 & 4.25039346768551 & 4.25039351936955 & 4.25039935164274 \\
\hline 0.8 & 4.59370586068823 & 4.59370563007463 & 4.59371217247398 \\
\hline 0.9 & 5.00676642428200 & 5.00676603087337 & 5.00677296919957 \\
\hline 1 & 5.50000000000000 & 5.50000000000000 & 5.50000595160000 \\
\hline
\end{tabular}

Table 4: The result maximum error when $n=4,6,11$ of example 2

\begin{tabular}{|c|c|c|c|}
\hline $\begin{array}{c}\text { Erro } \\
\mathrm{r}\end{array}$ & Hermite & Hermite & Hermite \\
& $H_{7}(\mathrm{x})$ & interpolation & interpolation \\
& $H_{11}(\mathrm{x})$ & $H_{21}(\mathrm{x})$ \\
\hline \multirow{2}{*}{ M.E } & 6.0524403950195 & 3.2687191368661 & 1.9597881395255 \\
& $8 \mathrm{e}-08$ & $6 \mathrm{e}-06$ & $3 \mathrm{e}-05$ \\
\hline
\end{tabular}

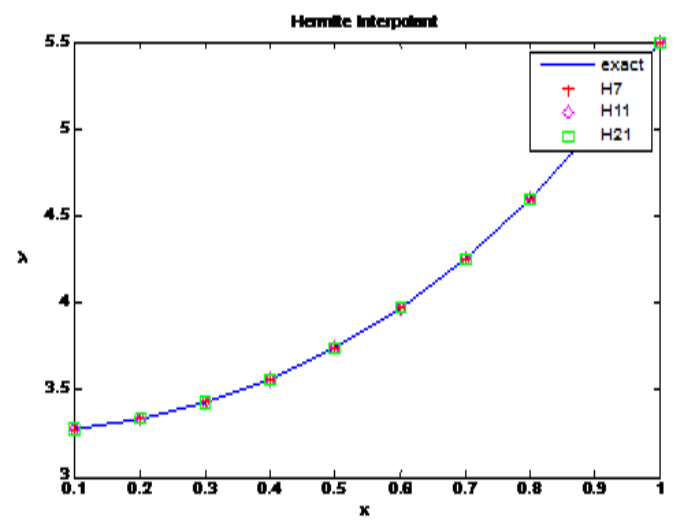

Fig.2: Comparison between the exact and suggested solution when $\mathrm{n}=4,6,11$

Example 3. consider the following SBVP: $\left(1-x^{2}\right) y^{\prime \prime}+x y^{\prime}+y=0 \quad, \quad 0$ $\leq \mathrm{x} \leq 1$

With Neumann BC : $y^{\prime}(0)=0, y^{\prime}(1)=$ - y(1) [11]

Using Taylor polynomials, we have $\mathrm{y}(0)=1.85779174711865, \mathrm{y}(1 / 3)=$ $2.076407841859629, \quad \mathrm{y}(2 / 3)=$ $2.02488427571492, \mathrm{y}(1)=$ 1.65096790760441614054343517637, $y^{\prime}(1 / 3)=\quad 0.2793960039864789$, $y^{\prime}(2 / 3)=-0.6144298559221, \quad y^{\prime}(1)=-$ 1.650967907604

Now, we solve this equation using these data

$\mathrm{H}_{7}(\mathrm{x})=-$

0.001499602844631908737937919795

$5132 x^{7}+0.008758728078627768 x^{6}-$ 
0.027426733964148297673091292381

$287 \mathrm{x}^{5}+\quad 0.07514319897959248 \mathrm{x}^{4}-$ 0.332863322735647670924663543701 $17 \mathrm{x}^{3}$

0.928936107025947421789169311523

$44 x^{2}+x+1.857791747118655$

The numerical results are given in and Table 5 gives $\mathrm{H}_{7}(\mathrm{x})$, results VIM exact solution. Table 6gives the maximum error for number point $\mathrm{n}=$ 4, 6, 11 . Figure 3 gives the accuracy of the suggested method.

Table 5: Numerical results for $n=4$ of example 3

\begin{tabular}{|c|c|c|}
\hline $\mathrm{X}_{\mathrm{i}}$ & $\mathrm{P}_{7}$ & Hermite interpolation $H_{7}(\mathrm{x})$ \\
\hline 0 & 1.857784296228232 & 1.85779174711866 \\
\hline 0.1 & 1.948169418187120 & 1.94817677138695 \\
\hline 0.2 & 2.018075735440336 & 2.01808339018278 \\
\hline 0.3 & 2.065740050052486 & 2.06574825787000 \\
\hline 0.4 & 2.089526555233489 & 2.08953495227793 \\
\hline 0.5 & 2.087906467474147 & 2.08791430899834 \\
\hline 0.6 & 2.059442143114885 & 2.05944879456718 \\
\hline 0.7 & 2.002774819034724 & 2.00278016273118 \\
\hline 0.8 & 1.916615117147540 & 1.91661963799949 \\
\hline 0.9 & 1.799735452392664 & 1.79973987068057 \\
\hline 1 & 1.650963483906875 & 1.65096790760442 \\
\hline
\end{tabular}

Table 6:the results maximum error when $n=4$ of example 3

\begin{tabular}{|c|c|c|c|}
\hline $\mathrm{Xi}$ & $\mathrm{H} 7^{\prime \prime}$ & $\mathrm{f}\left(\mathrm{x}, \mathrm{H} 7(\mathrm{x}), \mathrm{H} 7^{\prime}(\mathrm{x})\right)$ & $\begin{array}{c}\text { Error } \mid \mathrm{H} 7^{\prime \prime}-\mathrm{f}(\mathrm{x}, \\
\left.\mathrm{H}(\mathrm{x}), \mathrm{H} 7^{\prime}(\mathrm{x})\right) \mid\end{array}$ \\
\hline 0 & -1.85787221405916 & -1.85779174711866 & $\begin{array}{c}8.04669405023439 \mathrm{e}- \\
05\end{array}$ \\
\hline 0.1 & -2.04909591215124 & -2.04911939063003 & $\begin{array}{c}2.34784787940256 \mathrm{e}- \\
05\end{array}$ \\
\hline 0.2 & -2.22522747898047 & -2.22522921308460 & $\begin{array}{c}1.73410413539798 \mathrm{e}- \\
06\end{array}$ \\
\hline 0.3 & -2.38870665496927 & -2.38869807607405 & $\begin{array}{c}8.57889522176691 \mathrm{e}- \\
06\end{array}$ \\
\hline 0.4 & -2.54149371208515 & -2.54149298894841 & $\begin{array}{c}7.23136737157404 \mathrm{e}- \\
07\end{array}$ \\
\hline 0.5 & -2.68514503382407 & -2.68514933766494 & $\begin{array}{c}4.30384087213298 \mathrm{e}- \\
06\end{array}$ \\
\hline 0.6 & -2.82088869519379 & -2.82088767638881 & $\begin{array}{c}1.01880497460627 \mathrm{e}- \\
06\end{array}$ \\
\hline 0.7 & -2.94970004269726 & -2.94969437953626 & $\begin{array}{c}5.66316099970265 \mathrm{e}- \\
06\end{array}$ \\
\hline 0.8 & -3.07237727431599 & -3.07238020853248 & $\begin{array}{c}2.93421649200099 \mathrm{e}- \\
06\end{array}$ \\
\hline 0.9 & -3.18961701949341 & -3.18962492996904 & $\begin{array}{c}7.91047562120895 \mathrm{e}- \\
06\end{array}$ \\
\hline & Max. Error & 1.85779174711866 & $\begin{array}{c}8.04669405023439 \mathrm{e}- \\
05\end{array}$ \\
\hline
\end{tabular}

Where $n=4,6,10$, then max. error:

$$
\begin{aligned}
& \left\|H_{7}^{\prime \prime}(\mathrm{x})-\mathrm{f}\left(\mathrm{x}, H_{7}(\mathrm{x}), H_{7}^{\prime}(\mathrm{x})\right)\right\|_{\infty} /(1 \\
& +\left\|\mathrm{f}\left(\mathrm{x}, H_{7}(\mathrm{x}), H_{7}^{\prime}(\mathrm{x})\right)\right\|_{\infty} \\
& =2.815703 \mathrm{e}-05
\end{aligned}
$$

$\left\|H_{11}{ }^{\prime \prime}(\mathrm{x})-\mathrm{f}\left(\mathrm{x}, H_{11}(\mathrm{x}), H_{11}{ }^{\prime}(\mathrm{x})\right)\right\|_{\infty}$ $/\left(1+\left\|\mathrm{f}\left(\mathrm{x}, H_{11}(\mathrm{x}), H_{11}{ }^{\prime}(\mathrm{x})\right)\right\|_{\infty}\right.$ $=0.000767$

$\left\|H_{21}{ }^{\prime \prime}(\mathrm{x})-\mathrm{f}\left(\mathrm{x}, H_{21}(\mathrm{x}), H_{21}{ }^{\prime}(\mathrm{x})\right)\right\|_{\infty} /$ $\left(1+\left\|\mathrm{f}\left(\mathrm{x}, H_{21}(\mathrm{x}), H_{21}{ }^{\prime}(\mathrm{x})\right)\right\|_{\infty}=\right.$ 0.003949

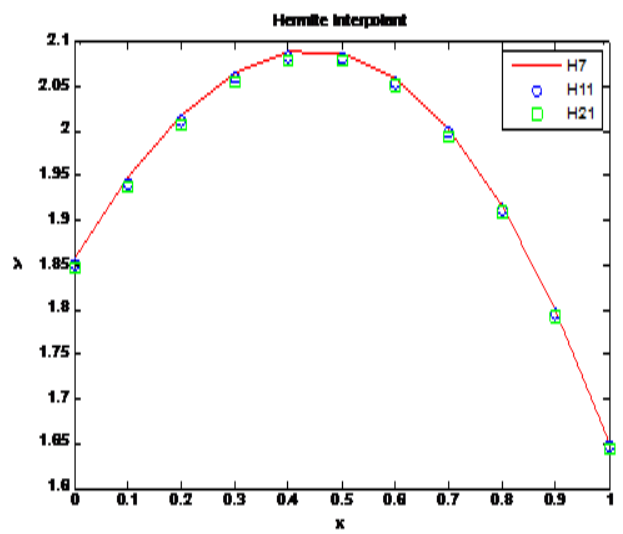

Fig. 3: Comparison the suggested solution when $n=4,6,11$

\section{Conclusion:}

In this paper Hermite interpolation method was used to solving singular boundary value problem. The result shown that the divided the domain into a number point follow the same steps as the previous is a very powerful and efficient in finding accurate solution for a large class of regular singular point.

\section{References:}

[1] Kadalbajoo, M. K. and Kumar V. 2007. B-spline method for a class of singular two-point boundary value problems using optimal grid. Appl. Math. Computa., 188(2) : 1856-1869.

[2] Jamet, P., 1970. On the convergence of finite difference approximations to one dimensional singular boundary value problems. Numer. Math.,14(4): 355-378

[3] El-Gebeily, M. A. and Abuzaid, I. T. 1998. On a finite difference method for singular two-point boundary value problems. IMA J. Numer, Anal,18(2): 179-190 . 
[4] Mahmoudi, M. and Kazemi, M. V. 2013. Solving singular boundary value problems of ordinary differenal equation by modified homotopy perturbation method. Appl Math. Comput. Sci., (7):138-143.

[5] Ravi Kanth, A. S. V. and Aruna, K. 2008. Solution of singular two point boundary value problems using differential transformation method. Phys. Lett. A, 372(26): 4671-4673.

[6] Gupta, Y. and kumar, M. 2011. A Computer based numerical method for singular boundary value problems. Int. J. Comput. Applic. 30(1):21-25.

[7] Ebaid, A. and Aljouf, M. D. 2012. Exact solutions for a class of singular two-point boundary value problems using adomian decomposition Method. Appl. Math. Sci.,6(122):6108 - 6097

[8] Koch, O. and Weinmüller, E. B. 2003. The convergence of shooting methods for singular boundary value problems. math. Comput., 72(241): 289-305.

[9] Tripathi, B. k. 2013. Solution of a class of singular two point boundary value problems by variational method. Math. comput. Sci. res.,6(3):35-39.

[10] Butcher, J. C.; Corless, R. M., Gonzale, L. and shakoori-Vega, A. 2011. Polynomial algebra for Birkhoff interpolants. Numer. Algorith., 56(3) : 319-347.

[11] Burden, L. R. and Faires, J. D. 2001. Numerical analysis. Seventh Edition.

[12] Rachůnková, I.; Staněk, S. and Tvrdý, M. 2008. Solvability of Nonlinear Singular Problems for Ordinary Differential Equations. Hindawi, New York, pp279.

[13] Shampine, F.; Kierzenka, J. and Reichelt, M. W. 2000. Solving Boundary Value Problems for Ordinary Differential Equations in Matlab with bvp4c. The Math Works, Inc., 24 Prime Park Way, Natick,MA.,pp1-27.

[14] Carnahan, B.; Luther, H. and Wilkes, J. 1990. Applied numerical methods. Robert E. Krieger Publishing Company, Inc.,Florida , pp 604.

[15] Geng, F. 2010. Variational iteration method for a class of singular boundary value problems. Math. Sci., 4(4): 359-370.

\section{حل مسألة القيم الحدودية الثـاذة ذات النقطتين باستخدام الاندراج هيرمت}

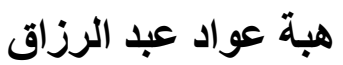

قسم الرياضيات، كلية العلوم للبنات، جامعة بغداد

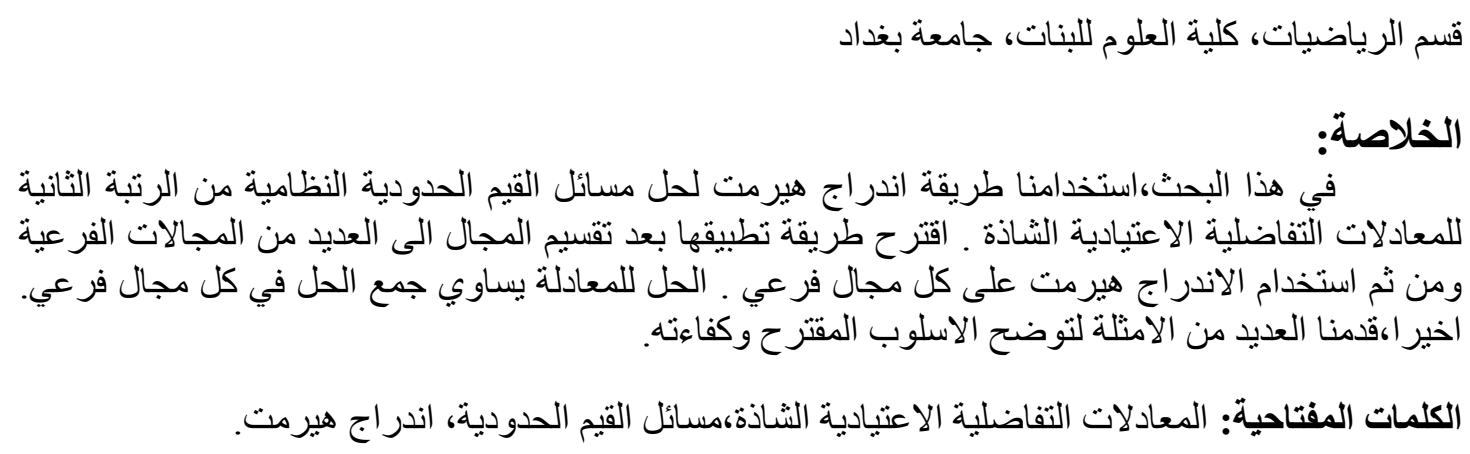

